\title{
Genetic interaction between HAP1/REF-1 and p53
}

$\mathrm{M}$ ice defective in the $X P C$ gene required for nucleotide excision repair (NER) of DNA are highly predisposed to skin cancer after exposure to UVB radiation (Fig. 1; refs $1-3$ ). The $p 53$ gene (also known as TP53) has also been implicated in the pathogenesis of cancers in mammals ${ }^{4}$. We previously reported that the onset of skin cancer is accelerated in $X P C^{-1-}$ animals with one $p 53$ allele deleted (Fig. 1; ref. 3 ). We now show that $X P C^{-1-} p 53^{-i-}$ mice are even more cancer prone than $X P C^{-1} p 53^{+/-}$ animals (Fig. 1). Hence, the absence of p53 protein provides a synergistic effect in promoting skin cancer in XPC mutant mice.

To investigate the role of base excision repair in environmental carcinogenesis, we have focused on the HAP1 gene, which encodes the major apurinic/apyrimidinic (AP) endonuclease in mammalian cells ${ }^{5}$. HAPl protein was independently discovered as a redox protein, which is required for the activation of oxidized AP-1 transcription factor ${ }^{5,6}$. Hence, HAP1 is also referred to as REF1 (redox function; refs 5,6 ). Homozygous deletion of mouse HAP1/REF1 results in embryonic lethality (L.B.M., D.L.C., R.E.H. \& E.C.F., unpublished observations; ref. 7). Heterozygous HAP1 mutants are viable, however, and grow normally.

We introduced the HAP1 heterozygous state into animals carrying mutations in the $X P C$ or $p 53$ gene and exposed them to UV radiation as described ${ }^{3}$. $X P C^{-1-} p 53^{+/+}$ $H A P I^{+1-}$ mice manifested accelerated skin cancer compared to $\mathrm{XPC}^{-1-} \mathrm{p} 53^{+/+} \mathrm{HAP1^{+/+ }}$ animals (Fig. 1). This effect was not observed in $X P C^{+/+} p 53^{+/+} \mathrm{HAPI}^{+1-}$ animals, which showed a skin-cancer rate indistinguishable from that in wild-type animals (Fig. 1). Significantly, the kinetics of cancer induction in $X P C^{-1-}$ mice that are additionally heterozygous for both $p 53$ and HAP1 was indistinguishable from that in $X P C^{-1-}$ animals heterozygous for just $p 53$ (Fig. 1). Furthermore, the kinetics of induction of skin cancer in $\mathrm{XPC}^{-1-} p 53^{-1-}$ double mutants was not enhanced by the HAP1 heterozygous state (Fig. 1). XPC $C^{+1+} p 53^{+1-} \mathrm{HAP1}^{+/-}$mice showed no increased cancer predisposition (Fig. 1). These observations suggest that inactivation of HAP1 or $p 53$ synergizes with defective NER by the same mechanism(s).

Recent biochemical studies have provided evidence that HAP1 is a potent acti-

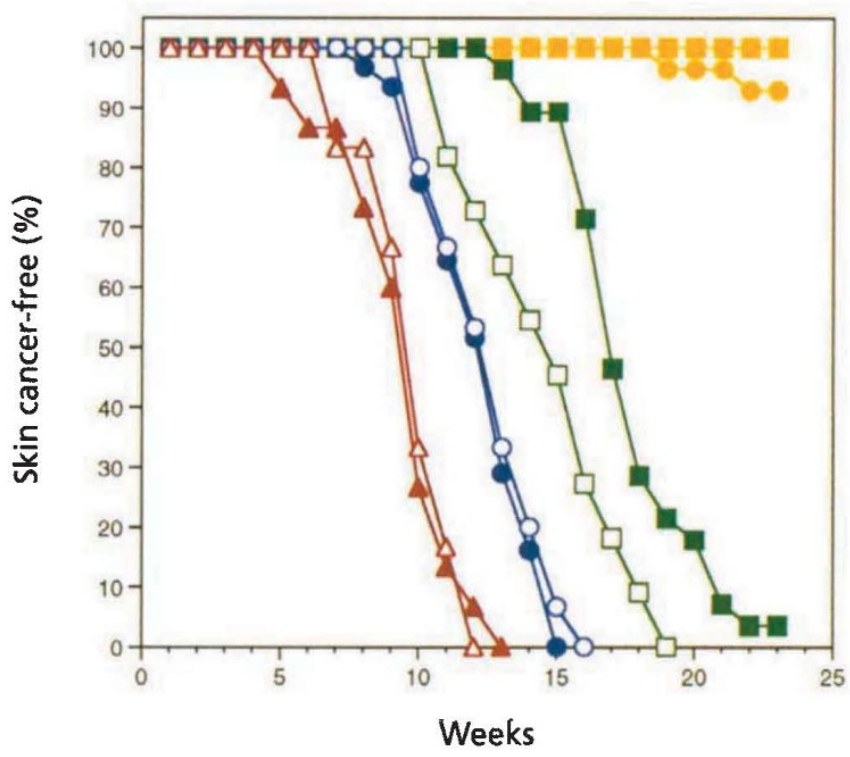

Fig. 1 Kinetics of radiation-induced skin cancer in mice. Animals were exposed to daily UVB radiation on the shaved dorsal skin as previously described ${ }^{3}$. Mice were examined and scored for skin cancers at least once a week, and all tumours were confirmed by histological examination. The

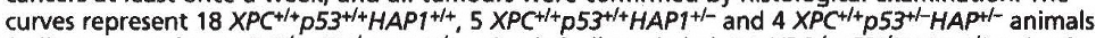
(yellow squares); $28 \mathrm{XPC}^{+1+} \mathrm{p} 53^{+1-} \mathrm{HAP1^{+1+ }}$ animals (yellow circles); $28 \mathrm{XPC}^{-1} \mathrm{p} 53^{+1+} \mathrm{HAP1^{+1+ }}$ animals (green squares); $12 \mathrm{XPC}^{-1-} \mathrm{p} 53^{+/+} \mathrm{HAP1^{+1- }}$ animals (green open squares); $30 \mathrm{XPC}^{-1} \mathrm{p} 53^{+1-} \mathrm{HAP1^{+1+ }}$ ani-

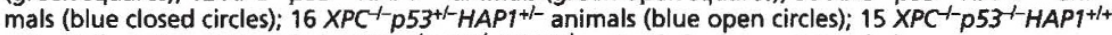
animals (red closed triangles); $6 \times \mathrm{PC}^{-1-} \mathrm{P} 53^{-1-} \mathrm{HAP1^{+- }}$ animals (red open triangles).

vator of p53, operating by both redoxdependent and redox-independent mechanisms ${ }^{8}$. Our experiments provide distinct genetic evidence that activation of p53 protein is HAP1 dependent. Hence, in $X P C^{-1-}$ animals with a deletion of one HAP1 allele, loss of the second allele in pre-neoplastic or neoplastic cells may render cells phenotypically $p 53$ null. The observation that $X^{-/-}$mice heterozygous for $H A P l$ are not quite as cancer prone as $\mathrm{XPC}^{-/-}$mice heterozygous for $p 53$ suggests that HAP1 may be less susceptible than $p 53$ to mutations that inactivate the function of $\mathrm{p} 53$ protein.

Because the redox function of HAP1 is apparently required for activation of oxidized AP-1 and possibly other transcription factors ${ }^{5,6}$, the possibility that defects in these functions might somehow account for the results observed cannot be formally discounted. Experiments to demonstrate and map the location of mutations in the second HAP1 allele in skin tumours from $X P C^{-1-} p 53^{+/+} \mathrm{HAP1}^{+1-}$ animals are in progress.
Acknowledgements

The contributions of L.B.M. and D.L.C. are considered equal. Studies were supported by a research grant from the USPHS (E.C.F.) and by fellowships from the ACS (D.L.C.) and Friends of the Center for Human Nutrition, University of Texas Southwestern Medical Center (L.B.M.).

Lisiane B. Meira', David L. Cheo', Robert E. Hammer², Dennis K. Burns', Antonio Reis ${ }^{1}$ \& Errol C. Friedberg ${ }^{1}$ ${ }^{1}$ Laboratory of Molecular Pathology, Department of Pathology, and ${ }^{2}$ Department of Biochemistry and Howard Hughes Medical Institute, University of Texas Southwestern Medical Center, Dallas, Texas 75237 USA. Correspondence should be addressed to E.C.F. email: friedberg.errol@pathology.swmed.edu

1. Cheo, D.L. et al. Mutat. Res. 374, 1-9 (1997).

2. Sands, A.T., Abuin, A., Sanchez, A., Conti, J.C. \& Bradiey, A. Nature 377, 162-165 (1995).

3. Cheo, D.L. et al. Curr. Biol. 6, 1691-1694 (1996).

4. Levine, A. Cell 88, 323-331 (1997)

5. Barzilay, G. Walker, L.J., Rothwell, D.G. \& Hickson, I.D. Br. J. Cancer 4 (Suppl. XXVII), S145-S150 (1996).

6. Xanthoudakis, S. Miao, G. Wang, F. Pan, Y.C.E. \& Curran, T. EMBO J. 11, 3323-3335 (1992).

7. Xanthoudakis, S., Smeyne, R.J., Wallace, J.D. \& . Xanthoudakis, S., Smeyne, R.J., Wallace, J.D. \&
Curran, T. Proc. Natl. Acad. Sci. USA 93, 8919-8923 (1996).

8. Jayaraman, L. et al. Genes Dev. 11, 558-570 (1997). 